\title{
Comparison between Conventional, Game-based, and Self- made Storybook-based Oral Health Education on Children's Oral Hygiene Status: A Prospective Cohort Study
}

\author{
Shivangi Sharma ${ }^{1}$, Smriti Saxena $^{2}$, Sathyajith N Naik ${ }^{3}$, Ravi Bhandari ${ }^{4}$, Anuj Kishor Shukla ${ }^{5}$, Puneet Gupta ${ }^{6}$
}

\begin{abstract}
Introduction: Dental caries is the most widespread disease affecting children worldwide. The reason for this increased prevalence is the use of more processed foods and beverages with the addition of refined sugars. General health affects oral health and its maintenance is of great importance. Lifestyle modifications and habits are formed at an early age therefore health education plays an important role in educating them about the prevention of problems related to oral health. Hence, the aim of this study was to assess and compare the effectiveness of conventional method, game-based and storybook-based oral health education on the oral hygiene status among 7-12-year-old schoolchildren. Purpose: To assess and compare the effectiveness of conventional method, game-based and storybook-based oral health education on the oral hygiene status among 7-12-year-old schoolchildren.

Materials and methods: A total of 300 children aged 7-12 years were divided into 3 groups. Each group had 100 children which were randomly assigned to each of the three groups. In group I, oral health education with the help of conventional method using educative posters was given to children once daily for a week. In group II, oral health education was imparted to children through play method (i.e., snakes and ladders game combined with flash cards) followed by group III, in which children were given education through self-made storybooks. The oral hygiene of all the children was estimated through Oral Hygiene Index-Simplified Debris (DI-S) score at day 1 and after 3 months after intervention.

Results: In group III, storybooks showed maximum reduction in debris score which was found to be highly statistically significant followed by game based (group II) and conventional method (group I) of oral health education.

Conclusion: The reduction in debris score was seen maximum in group III (storybooks). Hence, the use of storybooks should be encouraged for educating children regarding basic oral health concepts.

Clinical significance: There is important need to understand differences in the mental cognitive ability of the children at different ages and the need to develop different intervention programs for different age-groups. Rationalizing reading can be an intelligent initiative toward the development of good oral habits and transforming the outlook of oral healthcare system in years to come.

Keywords: Health education, Oral hygiene status, Schoolchildren, Storybooks.

International Journal of Clinical Pediatric Dentistry (2021): 10.5005/jp-journals-10005-1811
\end{abstract}

\section{INTRODUCTION}

Oral health is a key component of general health and is a crucial element of a child's well-being. Poor oral health can have a harmful effect on children's quality of life. The most common oral disease encountered by children is dental caries. With the increased availability of processed foods and beverages, children are at the cutting edge of the disease disadvantage. Children and adolescents are quick to receive new information, and the earlier healthy oral habits are established, the greater is their impact. During adolescence, young people are able to assume responsibility for learning and maintaining health-related attitudes and behaviors that carry over into adulthood. ${ }^{1-3}$

A school is a closed environment that concentrates a considerable number of individuals of the same age group who regularly attend the institution. For this reason, it has been considered ideal for developing health and oral hygiene programs with children in age groups that are favorable for adopting preventive measures. Health promoting programs which are school based are known to us since many years in the form of single lectures and demonstrations. However, it has been explored
1,3 Department of Pedodontics and Preventive Dentistry, Institute of Dental Sciences, Bareilly, Uttar Pradesh, India

${ }^{2}$ Department of Public Health Dentistry, Institute of Dental Sciences, Bareilly, Uttar Pradesh, India

${ }^{4}$ Department of Orthodontics and Dentofacial Orthopedics, Institute of Dental Sciences, Bareilly, Uttar Pradesh, India

${ }^{5}$ Department of Prosthodontics, Crown and Bridge and Implantology, Institute of Dental Sciences, Bareilly, Uttar Pradesh, India

${ }^{6}$ Department of Public Health Dentistry, Government College of Dentistry, Indore, Madhya Pradesh, India

Corresponding Author: Shivangi Sharma, Department of Pedodontics and Preventive Dentistry, Institute of Dental Sciences, Bareilly, Uttar Pradesh, India, Phone: +91 9627705646, e-mail: dr.shivi30@gmail.com How to cite this article: Sharma S, Saxena S, Naik SN, et al. Comparison between Conventional, Game-based, and Self-made Storybook-based Oral Health Education on Children's Oral Hygiene Status: A Prospective Cohort Study. Int J Clin Pediatr Dent 2021;14(2):273-277.

Source of support: Nil

Conflict of interest: None

(0) Jaypee Brothers Medical Publishers. 2021 Open Access This article is distributed under the terms of the Creative Commons Attribution 4.0 International License (https://creativecommons.org/licenses/by-nc/4.0/), which permits unrestricted use, distribution, and non-commercial reproduction in any medium, provided you give appropriate credit to the original author(s) and the source, provide a link to the Creative Commons license, and indicate if changes were made. The Creative Commons Public Domain Dedication waiver (http://creativecommons.org/publicdomain/zero/1.0/) applies to the data made available in this article, unless otherwise stated. 
that there is no effect of such demonstrations on the status of oral hygiene among children. ${ }^{4-6}$ Despite the inability of these programs to achieve good oral hygiene, they are still continued to provide education in schools. So, it was proposed that to benefit the oral health status of the children in schools, programs should be conducted in a more understanding, descriptive, and narrative way. ${ }^{7}$

The process of learning can be made a joyful activity for children's oral health with the collaboration of education with entertainment. There are various modes of cost-effective media and materials available which can be used to make learning both interesting and effective. Interactive learning has many advantages, such as attention span increased, and also helps in reviving memory with more develops their visual alertness, increases their attention span, and also assists with memory strategies and reasoning. ${ }^{8}$ Game-based teaching is an educational strategy that facilitates and reinforces a child's learning in a stimulating and dynamic format. Although previous studies have supported the effect of game-based intervention and conventional intervention on oral hygiene intervention but there are no studies using self-made dental storybooks that were focused on oral hygiene intervention. ${ }^{9}$

As Ursula LeGuin said, "There have been great societies that did not use the wheel, but there have been no societies that did not tell stories." Oral storytelling has been part of human existence for millennia. ${ }^{10}$ The present study is the newest of its kind, with the aim of comparison of the effectiveness of conventional and gamebased teaching with new preparatory aid (dental storybooks) on the level of oral health knowledge and oral hygiene status among 7- to 12-year-old schoolchildren.

\section{Materials and Methods}

The study protocol was reviewed and approved by the Institutional Review Board of the Institute of Dental Sciences in accordance with the Helsinki Declaration of 1975, as revised in 2013. Informed written consent was obtained from the parents of all the participating children. The study was conducted in an elementary school of Bareilly city in Uttar Pradesh, India. For this study, total 472 children out of which 300 schoolchildren were randomly selected aged 7 to 12 years using a table of random numbers generated through entering the data in the computer. Inclusion criteria were children within the age-group 7 to 12 years, children who obtained informed voluntary written consent from their parents/ guardian to participate in the study, and children present on the day of examination. Exclusion criteria were physically and mentally challenged children and children with systemic disease.

Of the 300 children from each age group, 100 were randomly assigned to group I and 100 to group II and group III. In order to calibrate for intra-examiner variability, five of the patients were reexamined by the examiner soon after and after few days. Kappa statistics was applied on the collected data and the coefficient of correlation was found to be in the range of 0.8 to 0.9 for the index. All the correlation coefficient values were found to be high reflecting high degree of concordance.

The pro forma for the present study was in English language. The pro forma had two components-sociodemographic data and clinical examination.

- Initial part with a provision to record sociodemographic information like age, gender, and general information.

- The final part included specifically designed index, i.e., Oral Hygiene Index-Simplified (OHI-S) Debris score (DI-S) given by the authors John C Greene and Jack R Vermillion to check the plaque accumulation among the study subjects (schoolchildren). To evaluate the debris index score along the tooth surface, the side of the explorer was by run parallel to that specific tooth being assessed. ${ }^{11}$ This index classifies oral hygiene by evaluating the extent of debris on six representative tooth surfaces: The buccal surface of the right maxillary primary or permanent molar, the labial surface of the right maxillary primary or permanent incisor, the buccal surface of the left maxillary primary or permanent molar, the lingual surface of the left mandibular primary or permanent molar, the labial surface of the left mandibular primary or permanent central incisor, and the lingual surface of the right mandibular primary or permanent molar. The criteria for scoring ranges from score 0 to score 3 and then children were given a debris score. Under standard aseptic conditions in natural daylight, the baseline examination of oral health was conducted in school premises by the dental students. The intervention was started after the estimation of DI-S score.

The educational approach was carried out by the undergraduate dental students under the guidance of two research investigators. A lecture based on oral health, brushing, and diet was given for 15 minutes. The dental students were trained for the presentation before delivering it at the school. About 100 children in group I were given oral health instruction through the conventional method using educative posters once a day for a week. About 100 children in group II were instructed using the game-based teaching method (snakes and ladders) combined with flash cards.

The game consisted of a checkerboard with numbers 1 to 100 , played by 5 children of the same age group. The coin moved with the corresponding numbers on the dice. If the player landed on the space at the bottom of the ladder (do's of good oral hygiene), he/ she climbed up the ladder to a space higher on the board. If the player landed on the space at the head of the snake (don'ts of oral hygiene), he/she slided down to the bottom of it, one space lower on the board. The do's and don'ts of oral hygiene were reinforced through flash cards each time, when the ladders and snakes took them up and down, respectively. The first player to reach 100 (attain good oral hygiene) was declared the winner. The rules of the game were clearly explained by the main investigator and they were allowed to play once a day for a week.

About 100 children in group III were given preparatory aid in the form of dental storybooks illustrating various modalities of oral hygiene maintenance and its role delineated using cartoon characters. The evaluations regarding oral hygiene index-simplified were recorded on postintervention 1st month and follow-up was performed after 3 months and the OHI-S was recorded again. The resulting data were coded and analyzed to assess intergroup differences.

\section{Statistical Analysis}

The data were entered in the excel spread sheet and were analyzed through the SPSS (Statistical Package for Social Sciences) software (IBM) version 21. The inferential statistics was applied where analysis of variance (ANOVA) test was used to analyze the differences among group means helpful in comparing three or more means for statistical significance $(p<0.05)$.

\section{Results}

Table 1 shows the Oral Hygiene Index-Simplified (OHI-S) Debris (DI-S) score among 7- to 12-year-old children in group I (conventional), 
group II (game), and group III (preparatory aid). At baseline, the mean debris score was seen maximum in conventional method and minimum in the subjects under preparatory aid. At 1st month, the mean debris score was found to be maximum in conventional method and minimum in the subjects under preparatory aid. At 3 months, the mean debris score was seen maximum in conventional method and minimum in the subjects under preparatory aid.

Table 2 shows reduction in debris score among 7-12-year-old children. From baseline to 1 month, the maximum reduction in debris score was seen among preparatory aid, which was found to be highly significant with $p<0.001$. From baseline to 3 months, the maximum reduction was seen among subjects of preparatory aid, which was also found to be highly significant with $p<0.001$.

Figure 1 shows the maximum reduction was seen in the storybooks when compared with the other two groups.

\section{Discussion}

In order to improve the oral health, many pediatric practitioners become annoyed when patients fail to follow the advice given to them. This is often seen as a sign of unconcerned, demotivation, and awareness among the patients, affirming the general opinion that oral hygiene still remains an ignored and unrealized major social problem even among literates. Research in dentistry has globally established the fact that prevention improves the bar of oral health education by bringing out the required behavioral changes. Childhood is the most influential time for children to develop and learn by doing, observing, and listening as young children are particularly receptive during this phase of growth WHO 1996. As children spend most of their time in schools so for health

Table 1: The distribution of data based on assessment of mean debris score among the study subjects

\begin{tabular}{lllll}
\hline \multirow{2}{*}{ Debris } & Groups & N & Mean & Std. \\
\hline At baseline & Conventional & 100 & 2.12 & 0.73 \\
& Game & 100 & 1.87 & 0.40 \\
& Preparatory aid & 100 & 1.76 & 0.40 \\
& Total & 300 & 1.92 & 0.55 \\
At 1st month after & Conventional & 100 & 1.79 & 0.68 \\
intervention & Game & 100 & 1.45 & 0.39 \\
& Preparatory aid & 100 & 1.22 & 0.39 \\
& & 300 & 1.49 & 0.56 \\
At 3rd month after & Total & 100 & 1.42 & 0.62 \\
intervention & Gonventional & 100 & 0.92 & 0.32 \\
& Game & 100 & 0.62 & 0.32 \\
& Preparatory aid & & & \\
& Total & 300 & 0.99 & 0.55 \\
\hline
\end{tabular}

promotion, schools are selected to be the most suitable place and remain the most common mode of creating oral health awareness in a cost-effective manner. ${ }^{12}$

On the contrary, extensive review showed that the schoolbased programs in the form of single lectures and demonstrations through flash cards, charts, and models are relatively ineffective as they provide information in a lesser time. So, oral health imparted in schools would give better results supervised in a more meaningful and understanding way. The present study is the first of its kind to put forth the effectiveness of storybooks as an oral health intervention based on Brain Friendly Learning Theory (BFL). ${ }^{13,14}$

This theory explained that how our brain functions to form comfortable surroundings important for learning. Young learners aged 7 to 12 years for the study group were selected as compared to adults because they are slow learners, physically active, emotionally excitable, get bored easily, forget things quickly, and are excellent mimics. Based on age, oral health interventions when undertaken must see the minor shift in every direction as it is important to adjust to their styles of teaching and strategies. ${ }^{15}$

Brain-based learning theory is based on how the brain receives and interprets information (Dwyer, 1998). It is a learning process to provide more natural conditions for learning to deeply understand the peculiarities of brain. It encourages new learning and teaching methods that appeal to various learning styles and intelligences with the objective of strengthening learning within lesser duration. ${ }^{16}$

The beliefs of BFL theory meet the requirements of children and their essential needs. The various aspects of this theory, such as emotions, motivational parts, memory, and thematic instructions, lay the stepping stone for adapting in the form of story. As stated by the Abrahamson et al., one of the most important inventions of human kind is the story. In education, stories are found in the form of written texts, oral narration, and instructional media. The storytelling is the art of relating a tale by creating mental images through acting or doing drama using the characters of a story through voice and gesture to the listeners. Henceforth, with the help of storytelling, learning experience is not only increased but there is complete engagement between the audience and the tellers. ${ }^{17}$

The proper growth and development starts when children start thinking for a better idea about the issues relevant to them. Emotions have a direct relationship with the memories due to which people of young age remember things better if there are things that give rise to emotions. While the subject of brain-based teaching is not particularly new, a teaching method that meets brain-based learning theories that has been receiving increasing attention is narrative storytelling. Storytelling is a form of communication means of teaching lessons and passing history down from one generation to another.

Table 2: The distribution of data based on reduction in mean debris score among the study subjects

\begin{tabular}{|c|c|c|c|c|c|}
\hline Reduction in debris score & Groups & $N$ & Mean & $S D$ & $p$ value \\
\hline \multirow[t]{3}{*}{ Baseline to 1st month } & Conventional & 100 & 0.33 & 0.14 & $<0.001$ \\
\hline & Game & 100 & 0.42 & 0.12 & \\
\hline & Preparatory aid & 100 & 0.54 & 0.16 & \\
\hline \multirow[t]{3}{*}{ Baseline to 3 months } & Conventional & 100 & 0.70 & 0.25 & $<0.001$ \\
\hline & Game & 100 & 0.95 & 0.21 & \\
\hline & Preparatory aid & 100 & 1.14 & 0.26 & \\
\hline
\end{tabular}




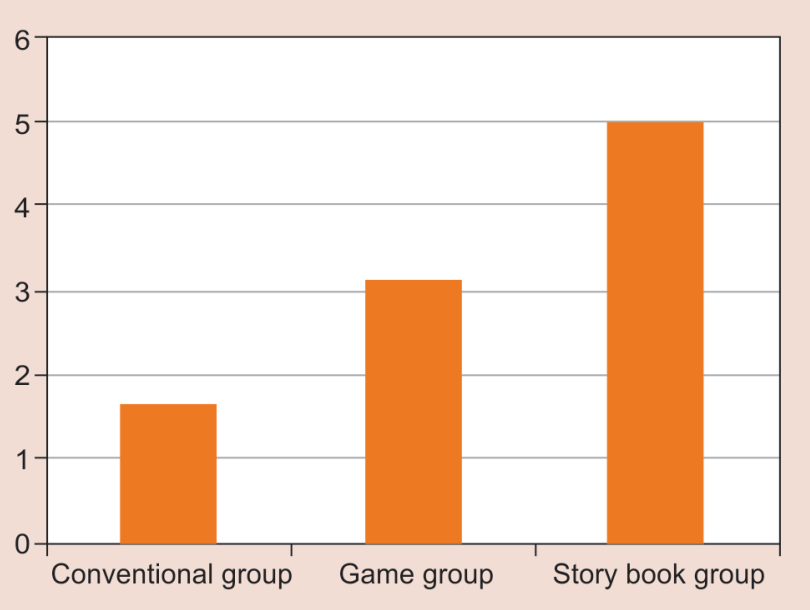

Fig. 1: The distribution of data based on maximum reduction in mean debris score among the study subjects

A study was presented in the proceedings of the National Academy of Sciences, which revealed that there was a close connection between listeners and the brain activity of speaker. The results indicated that the potential for rich learning experiences can be raised by engaging students with compelling stories both emotionally and biochemically.

It is found from the previous research that stories elicited emotions which increased the effectiveness of learning because learning experiences associated with emotions are not difficult to be restored and recalled. In an article by Rossiter stated that many teaching methods do not engage students on a level that storytelling does. In a qualitative research by Abrahamson et al. found that not only do learners hear the information but they are immersed in the contention a deeper and richer level through emotional and personal connections and visual imagery. Similarly, in a previous research conducted by Perry also suggested that when stories developed emotions, the cognitive parts of the brain were activated to store the new information. In a report by Richter and Koppett, it was concluded that due to the level of active engagement created storytelling has many of the benefits in experiential learning. ${ }^{17-20}$

The vivid images stimulated by storytelling promote character identification, thus engaging the student as an active participant in the learning process. When learners are engaged in this way, research reveals improved understanding and ability of the learner to apply what they have learned in the work setting. Storytelling addresses various learning patterns in terms of audiovisual and kinesthetic with areas of intelligence, such as spatial, linguistic, interpersonal, and intrapersonal intelligence.

For both child and adult education, games are been used as a teaching strategy since very long time and helps in promotion of self-learning and participation. According to Mohd Hafis Muaddab snake and ladder game was created in the 2 nd century BC by name of "Parmapada Sopanam" (ladder to salvation). The game was developed to teach children a lesson of mortality.

In a study conducted by Castillo Lizardo to analyze the effectiveness of an educational strategy based on children's game for teaching basic health concepts to school-age children and the findings from the results showed that using games, which includes health and hygiene measure can be an alternative to basic health concepts for teaching. ${ }^{21}$ Also, in a similar study performed by
Uma N Maheshwari investigated the effects of both conventional and game-based oral health education on children's oral healthrelated knowledge and oral hygiene status and the results revealed that the game-based oral health education program can be easily implemented and is cost-effective method for oral health awareness. $^{22}$

The present study planned used storybooks as an innovative and inspiring education tool for stimulating imaginations, enhancing critical thinking, and creating the interactive sessions between the storyteller and the listener, which was compared to games and conventional lecture method. In the present study, school students were randomly divided into three groups (group I comprised of lecture sessions, group II consisted of dental snake and ladder game, group III included usage of storybook). The knowledge and debris score was assessed in the three groups postintervention day 1 unless attitudes and habits are developed and put into practice, little will be gained and in order to develop habits sufficient time is required therefore, a follow-up was also performed at 3 months to evaluate the knowledge and debris score. Storytelling appeals to auditory, visual, and kinesthetic learning styles and many of the intelligence areas including spatial, linguistic, interpersonal intelligence, this was also very well reflected in our study where, knowledge gain and improvement in OHI-S score was maximum in group III followed by group II and I both at postintervention day 1 and 3 month follow-up.

Knowledge score and OHI-S score improved in group II also though the effectiveness of games in teaching and learning process was less as compared to storybooks only in the present study. As, games involve functional cognitive maturation in visual field only in contrast to storybooks which are multisensory in nature and involves both visual and auditory coordination. Moreover, winning or advancing in the game also takes a leap in some set of children and looking at variables, gaining knowledge thus, become secondary in these children, thereby deflecting from the main objective of gaining knowledge.

The other disadvantages associated with the game-based learning for students includes difficulty in understanding all the levels of game, establishment of a deadline for the students to end the game resulting in discouragement and low self-esteem and also the different decisions that students may take while playing the game also may lead to different learning materials or contents which may further result in the teachers difficulty to identify if and what students have learnt, and inability to find possible flaws/gaps in the evaluation.

In lecture sessions, student's attention wanes after few minutes creating lack of interest and motivation. The information delivered also tends to be forgotten quickly when students are passive because there is no mechanism to ensure that they are intellectually engaged with the material. These reasons contributed possibly to the least reduction in debris score in group I.

\section{Limitations}

The present study included only 300 children. Therefore, a study with larger sample size is strongly recommended. A possible limitation is the limited follow-up period of 3 months which may not allow up growth of dental health messages.

\section{Conclusion}

Oral hygiene awareness among children right from their young age can be made a joyful activity with the collaboration of 
education with entertainment through dental books. As, colorful lively illustrations, understandable language develops a better understanding and learning how to care for your teeth fun. Moreover, healthy habits and happy dental experience by cartoon superheroes give them something great to imitate.

In today's world of smart classes clubbing education and joyful activities are the smart move toward the generation next and help them making caring for teeth fun. So, promoting health to entire population and focusing on an action at a community level should be our motto but, for that dental professionals need to reorient their perspectives away from "traditional view" to the "intellectually modified gaze".

New preparatory aid (storybooks) replacing the conventional methods of oral health awareness stand out to be a remarkably worthy investment by dental fraternity to the most valuable mass (children) of the nation taking a great step toward better India. Therefore, we can conclude that the important lesson learnt from this research is that stories can add phenomenal richness every day.

\section{Clinical Significance}

Right amount of knowledge in right manner in right population can have an ever lasting impact and be of great help toward sustainable changes in our society. Knowledge thus imparted with right psychological, psychosocial, cognitive, and neuroscientific considerations in a child friendly manner can have a deep-rooted effect and can be used as an inseparable tool to spread awareness among masses, allay fear and anxiety in children, and in longer run can help uplift the face of dentistry in developing nation.

\section{References}

1. Kapoor D, Gill S, Singh A, et al. Oral hygiene awareness and practices amongst patients visiting the dental college in North India. Indian J Dent 2014;5(2):64-68.

2. Duke ES. Taxonomy of games and simulations for nursing education. J Nurs Educ 2006;25:197-206.

3. Nachiappan S. Snake and ladder games in cognition development on students with learning difficulties. Rev Arts Humanit 2014;3(2): 217-229.

4. Dunlosky J, Rawson KA, Marsh EJ, et al. Improving students learning with effective learning techniques: Promising directions from cognitive and education Psychology. Assoc Psychol Sci 2013;14(1): 4-58.
5. Kwan SYL, Petersen PE, Pine CM, et al. Health-promoting schools: an opportunity for oral health promotion. Bulletin of the WHO 2005;83(9):677-685.

6. Greene JC, Vermillion JR. The simplified oral hygiene index. J Am Dent Assoc 1964;68:7-13.

7. Marshall TA. Caries prevention in pediatrics: dietary guidelines. Quintessence Int 2004;35:332-335.

8. Moynihan P, Petersen PE. Diet, nutrition and the prevention of dental diseases. Public Health Nutr 2004;7(1A):201-226.

9. Moynihan PJ. The role of diet and nutrition in the etiology and prevention of oral disease. Bull World Health Organ 2005;83: 694-699.

10. Lynagh M, Schofield MJ, Sanson-Fishe RW. School health promoting programmes over the past decade: a review of the smoking, alcohol and solar protection literature. Health Promotion Int 1997;12: 43-60.

11. Basic Oral Health Survey Manual by WHO. 5th edition., 1997. pp. 25-35.

12. World Health Organization. The status of school health. Report of the School Health Working Group and the WHO Expert Committee on comprehensive school health education and promotion. Geneva: WHO; 1996.

13. Sprod A, Anderson R, Treasure E. Effective oral health promotion. Literature review. Health Promot Wales Techn Rep 1996. 20.

14. Telner D, Bujas M, Bobanovic M, et al. Game-based versus traditional case-based learning, comparing effectiveness in stroke continuing medical education. Can Fam Physician 2010;56:345-351.

15. Bonomo V. Brain-based learning theory. J Educat Human Develop 2017; 6(1):27-43.

16. Dwyer B. Training strategies for the 21st century: using current recent research on learning to enhance training. Innovat Educat Teach Int 2002;39(4):265-270.

17. Abrahamson C. Storytelling as a pedagogical tool in higher education. Education 1998;118(3):440-443.

18. Rossiter M. Narrative stories in adult teaching and learning. Eric Digest, 2002. 1-8.

19. Perry BD. How the brain learns best. Psycholog Foundat Organizat Behav. Scholastic Inc 2000;110(4):1-4.

20. Richter $M$, Koppet $K$. How to maximize training efficiency through storytelling, Retrieved on 2nd April 2020 from http://www. thestorynet.com/articles_essay/retention_article.com.

21. Castillo Lizardo JM, Rodriguez Moran M, Guerrero Romero F. Games as an alternative for teaching basic health concepts. Am J Public Health 2001;9:311-314.

22. Maheswari UN, Asokan S, Asokan S, et al. Effects of conventional vs. game-based oral health education on children's oral health-related knowledge and oral hygiene status - a prospective study. Oral Health Prev Dent 2014;12(4):331-336. 